\title{
A Model for the Development of A Chatter Bot/Chat Bot for Field of Public Health using the Example of Automated Online Breast Feeding Helper
}

\author{
Himanshi. H. L.N ${ }^{1 *}$ Karunathilake. I. $\mathrm{M}^{2 \#}$ \\ Faculty of Mathematics and Information Technology Engineering, University of Lodz, Poland \\ 'Facuty of Medicine, University of Colombo, Colombo, Sri Lanka \\ *nishihimanshi@gmail.com, ${ }^{*}$ karunathilake@ hotmail.com
}

\section{ABSTRACT}

The purpose of this paper is to provide a reference mode for the development of a chatter bot for field of Public Health using the example "Breast Feeding Helper". This project a carried out using the AIML language and the platform" Pandorabot". Use of Chat bot is new to the field for public health. The motivation behind this work is to make an initiative and demonstrate that it is feasible to develop a chatbot for the field of public health. This paper illustrates the steps and process of developing a chat bot for a topic in the field of public health. The steps and process described could be used as a model for further work.

Key words- Artificial Intelligence, Chatterbot, Pattern Recognition, Artificial Intelligence Markup Language (AIML)

\section{INTRODUCTION}

Breastfeeding is a natural process that involves feeding of babies with milk from a woman's breast and provides many health benefits for both the mother and infant [1]. Public health experts recommend heath education to promote breastfeeding [2].

Many women access websites and online forums to get information on breastfeeding [3, 4]. However many of these websites only provide set answers for frequently Asked Question (FAQ) and lack human-like responses and interactivity. Furthermore, there is no guarantee on the reliability of the information provided.

A Chabot (also known as chatterbot) is a computer program designed to simulate how a human-like conversation partner [5]. Currently chatbots are widely used for entertainment and marketing purpose. and customer service [6, 7]. However, as illustrated by the audience visualization chart of twitter (Figure 1) use of chatbot in the field of Public health is limited. The scientific literature related to this area is very limited. The motivation behind this work is to make an initiative to demonstrate that it is feasible to develop a chatbot for the field of public health so that peer researchers will be motived to make further contributions and expand the current body of knowledge. This paper will describe steps involved in the development of a chat bot for field of Public Health using the example of "Breast Feeding Helper".

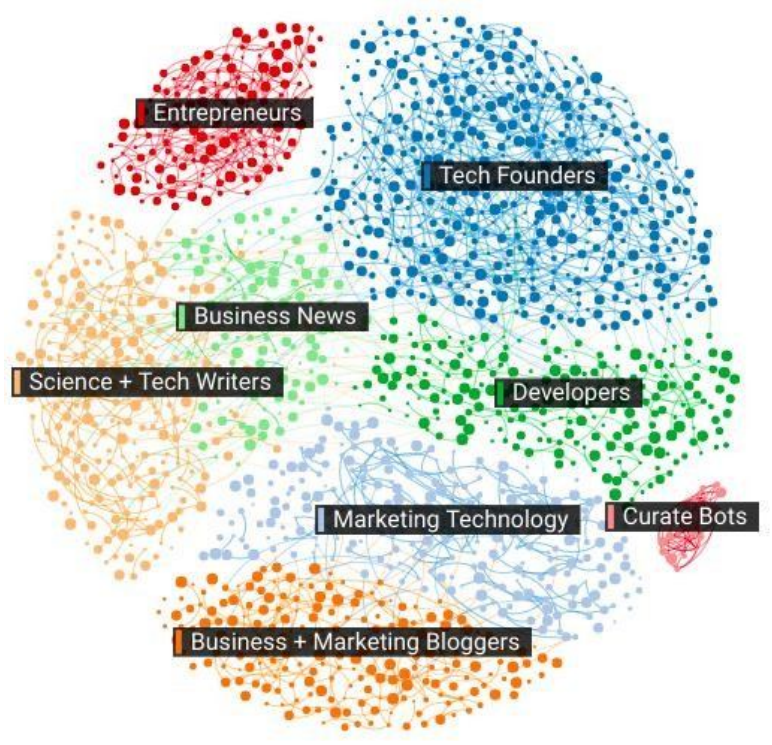

Figure 1: Audience visualization chart of twitter on use of chatbot

\section{RESEARCH PROBLEM \& OBJECTIVES}

The research problems was "What are the steps involved in the developing a chat bot for field of Public Health". Following objectives were identified based on the above research problem.

- Identify the content areas for the chatbot

- Compare and contrast different programmes to develop a chatbot. 
- Design and develop an automated online breast
feeding helper (a ChatBot) to provide reliable and human-like responses for FAQs on breastfeeding as an example for the field of Public Heath

- Evaluate the chatbot using peer feedback and technical analysis. Method

Medical literature was reviewed to identify frequently asked questions regarding breastfeeding and appropriate evidence based answer for them [2]. A sketch of the conversation was designed according to the identified FAQs.

Properties of different chatbot programme were considered and Pandorabot was elected a the appropriate platform (Table 1)

Table 1: Comparison of Different Chatbot Programmes

\begin{tabular}{|c|c|c|c|}
\hline Platform & Costs & Choose this one & Limitations \\
\hline Motion.ai & $\begin{array}{l}\text { Free to } \\
\$ 100 a\end{array}$ & $\begin{array}{l}\text { When want to } \\
\text { build a simple }\end{array}$ & $\begin{array}{l}\text { Can't set out } \\
\text { specific questions }\end{array}$ \\
\hline $\begin{array}{l}\text { Pandora } \\
\text { bots }\end{array}$ & Free & $\begin{array}{l}\text { Based on the } \\
\text { AIML }\end{array}$ & $\begin{array}{l}\text { The web-based UI is } \\
\text { still in beta }\end{array}$ \\
\hline Bot Libre & $\begin{array}{l}\text { Free to } \\
\$ 200 a\end{array}$ & Attractive & $\begin{array}{l}\text { Problems with } \\
\text { technology }\end{array}$ \\
\hline Chatbot4u & $\begin{array}{l}\text { Pro is } \$ 29 \\
\text { per month }\end{array}$ & Powerful tools & Needs expertise \\
\hline
\end{tabular}

Coding was written in Artificial Intelligence Markup Language (AIML) [8,9]. An example of coding is illustrated in Figure 2.

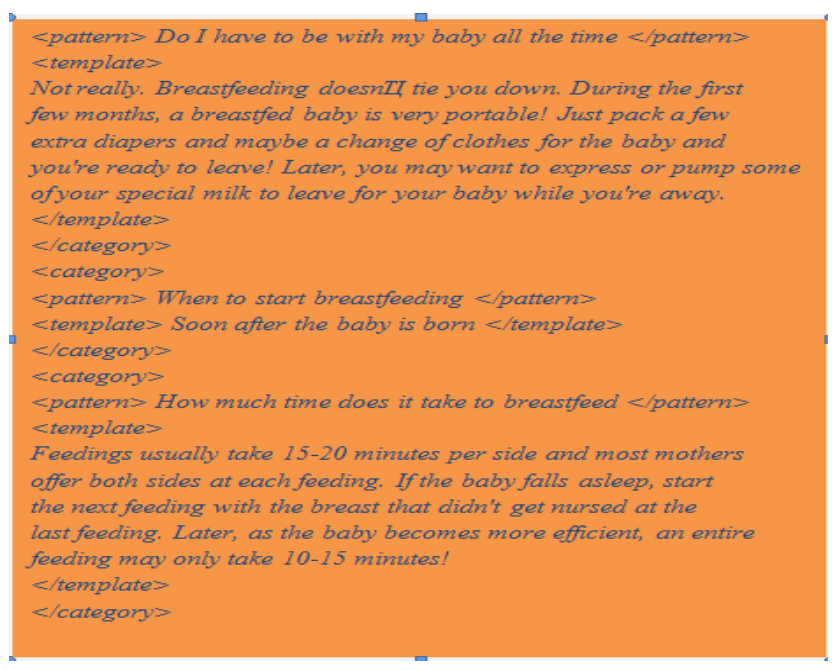

Figure 2: Screenshot of the codings
Several keywords were identified as possible inputs. Reponses to variations were ensured using wildcard options. Human-like response was imitated by making the ChatBot respond in full sentences. Ongoing conversation was achieved by building responses out of two parts: a reaction to the input in which sometimes a part of the input was repeated, added with a question or new statement.

The functioning of ChatBot was tested by performing a Turing test. The programme was evaluated by two peers who provided feedback.

\section{RESULTS}

Over 100 FAQs and relevant responses were identified. A ChatBot was developed in the program Pandorabot. Chatbot included 80 responses, 40 keyword and wildcards. The Chatbot was published online (Figure 3).

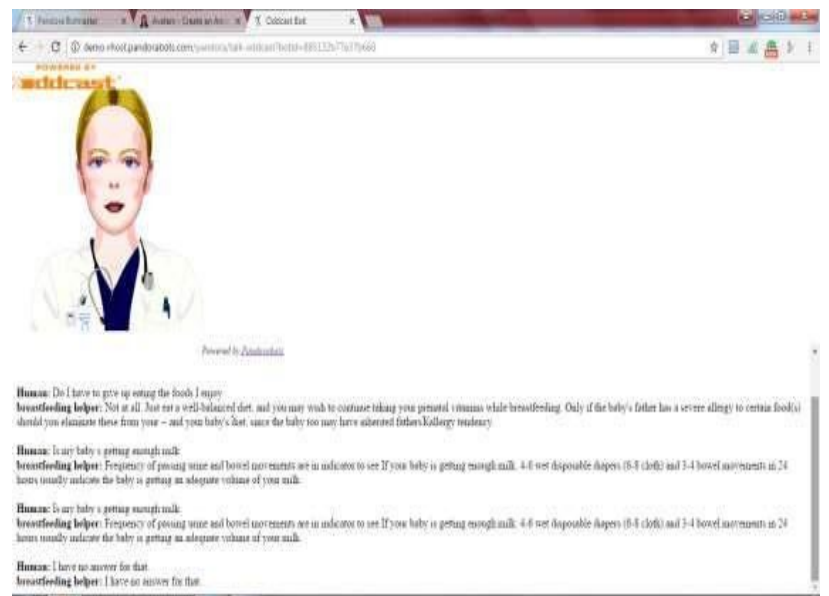

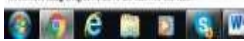

Figure 3: Screenshot of the Chatbot Interface

Turin test suggested that the responses were very realistic and human-like. However sometimes exactly the example sentences are used there can be an ongoing conversation.

The ChatBot was not capable of asking counter-questions. Peer feedback indicated a good coverage of the content domain and suggested improving the interactivity of the Chatbot.

\section{CONCLUSION}

Use of Chat bot is new to the field for public health. Therefore it is important to take an initiative and gradually expand on the current body of literature which is very limited. It is possible to develop a Chatbot to provide reliable and human-like responses for FAQs on breastfeeding. Chatbots thus developed could be evaluated using peer feedback and Turin test. The steps of the development process described in this paper could be used as a model for the development of a chat bots for field of Public Health. 


\section{REFERENCES}

[1] R. A. Lawrence and R.M. Lawrence, Breastfeeding: A Guide for the Medical Profession. Elsevier Health Sciences. 2011, pp. 227-228.

[2] S. Haroon, J.K. Das, R.A. Salam, A, Imdad, Z.A. Bhutta, Breastfeeding promotion interventions and breastfeeding practices: a systematic review, BMC Public Health, vol. 13, S. 20, 2013

https://doi.org/10.1186/1471-2458-13-S3-S20

[3] W.D. Evans, L.C. Abroms, R. Poropatich, P.E. Nielsen and J.L.Wallace, Mobile health evaluation methods: The Text4baby case study, Journal of Health Communications, vol.17, pp. 22-29, 2012. https://doi.org/10.1080/10810730.2011.649157

[4] D. Cassar-Uhl, P. Liberatos, Emerging trends in breastfeeding practice: improving lactation care through partnerships and technology, 143rd Annual Meeting of American Public Health Association, Chicago, USA, 2015

[5] B. Abu Shawar, and E. Atwell, A chatbot system as a tool to animate a corpus. ICAME Journal,. vol. 4, 29, pp. 5-24, 2005

[6] J. Chai, and J. Lin, The role of a natural language conversational interface in online sales: a case study, International Journal of Speech Technology, vol. 4, 2001, pp. 285-295

https://doi.org/10.1023/A:1011316909641

[7] S. Laven, "The Simon Lave Page", Available at: http://www.simonlaven.com, 2013

[8] R. Wallace, R. The Elements of AIML Style, ALICE A.I Foundation, 2001.

[9] R. Walace, R.S. AIML Overview. Retrieved from http://www.pandorabots.com/pandora/ pics/wallaceaimltutorial.html, 2016 